\title{
Review \\ Biology and therapy of fibromyalgia Stress, the stress response system, and fibromyalgia
}

Manuel Martinez-Lavin

National Institute of Cardiology, Juan Badiano 1, 14080 Mexico City, Mexico

Corresponding author: Manuel Martinez-Lavin, mmlavin@infosel.net.mx

Published: 6 July 2007

Arthritis Research \& Therapy 2007, 9:216 (doi:10.1186/ar2146)

This article is online at http://arthritis-research.com/content/9/4/216

(c) 2007 BioMed Central Ltd

See related editorial by Eisinger, http://arthritis-research.com/content/9/4/105

\begin{abstract}
Stress is a state of disharmony, or threatened homeostasis. A stressor could have a psychological origin or a biological origin. Societies have become more intricate with industrialization, and modern individuals try to adapt to the new defiance by forcing their stress response system. The main component of the stress response network is the autonomic nervous system. The present article reviews current knowledge on autonomic dysfunction in fibromyalgia. Sympathetic hyperactivity has been consistently described by diverse groups of investigators. Fibromyalgia is proposed to be a sympathetically maintained neuropathic pain syndrome, and genomic data support this contention. Autonomic dysfunction may also explain other fibromyalgia features not related to pain.
\end{abstract}

\section{Introduction}

Living organisms survive by maintaining harmonious equilibrium or homeostasis. Stress can be defined as a state of disharmony, or threatened homeostasis. For human beings a stressor could have a psychological origin (ongoing anger, anxiety, or depression) but can also originate from a biological insult (an infection, a burn, or a myocardial infarction). The term stress or stressor should therefore not be restricted to psychological events but, rather, should be viewed in an ample physiological context.

The stress response system is a delicate, dynamic system that vertebrate animals have in order to maintain homeostasis. The main components of this system are the autonomic nervous system (ANS) and the hypothalamic-pituitary adrenal axis. These two branches closely interact with each other and have positive reverberating feedback loops at different levels. If the capacity of the stress response system to adapt is overwhelmed, chronic diseases may appear [1].

Evolution imposes new challenges on all living organisms. Human societies have become more intricate and stressed with industrialization. An example of the new defiance is the alteration in the circadian rhythm. For many thousands of years, the day and night cycles were harmonious with external cues: light, noise, and activity during the day; darkness, rest, and quietness at night. In past decades, however, industrialization has clearly disturbed this harmony. Nowadays there can be light, activity, and noise at night. This and many other stressors of modern societies undoubtedly have an impact on human health.

Research performed in the past decade with novel instruments has shown that patients with fibromyalgia (FM) frequently have dysfunction of the stress response system. Furthermore, emerging clues propose that such dysfunction may be important in the pathogenesis of the syndrome. The present article attempts to update recent research on the behavior of the principal component of the stress response system, the ANS, in patients with FM.

\section{Autonomic nervous system}

The ANS is the main regulatory system of the body in charge of maintaining essential involuntary functions, such as the socalled vital signs (blood pressure, pulse, respiration, and temperature). The ANS balances the function of all internal organs, with the heart rate, intestinal motility, urination, and sexual activity, among many other variables, all regulated by the system.

One striking characteristic of the ANS network is the rapidity and intensity of onset of its action and its dissipation. The ANS is activated by centers located in the spinal cord, brain stem hypothalamus, and thalamus. These centers also receive input from the limbic area and other higher brain regions. Emotions (fear, anger, and panic) therefore have immediate biological responses (pupil dilation, paleness, and 
tachycardia). The ANS may be viewed as the interface between mind and body functions in charge of the basic fight or flight reaction.

The peripheral autonomic system is divided into two branches; sympathetic and parasympathetic. These two divisions have antagonistic actions on most bodily functions and thus their proper balance preserves homeostasis. The action of these two branches is mediated by neurotransmitters. Catecholamines are the sympathetic neurotransmitters. The naturally occurring catecholamines are norepinephrine, epinephrine, and dopamine. The three substances act as neurotransmitters within the central nervous system. Norepinephrine transmits impulses also in peripheral postganglionic nerve endings and exerts its effects locally, in the immediate vicinity of its release, whereas epinephrine is the circulating hormone of the adrenal medulla and influences processes throughout the body [2].

The major metabolic transformation of catecholamines involves methylation and oxidative deamination. Methylation is catalyzed by the enzyme catechol-O-methyltransferase (COMT) and occurs throughout the body, whereas oxidative deamination is promoted by monoamine oxidase and takes place mainly in the synaptic cleft. The COMT gene is located in region q11.21 of chromosome 22. This gene has abundant functional polymorphism. The better known transition occurs in codon 158 with a guanine-to-adenosine substitution, a polymorphism that results in functional alterations of the corresponding enzyme. The val/val genotype gives rise to an effective enzyme whereas the met/met genotype produces a 'lazy' enzyme unable to effectively clear catecholamines from the system [3].

Recent research has found other frequent polymorphisms of the COMT gene that induce an even more defective enzyme. Most of these newly found polymorphisms are in linkage disequilibrium with the val-158-met transition. These polymorphisms can be grouped into 'haplotypes'. It has been shown that a particular COMT gene haplotype named HPS gives rise to a defective enzyme, 11 times less efficient than the enzyme generated by the LPS haplotype. Interestingly, this HPS haplotype is associated with high pain sensitivity in healthy females [4]. This newly generated evidence supports the notion that the intensity of sympathetic function is in part genetically determined, and that a 'hyperadrenergic state' is associated with pain hypersensitivity.

\section{Clinical assessment of autonomic nervous system function}

The function of the ANS has been difficult to evaluate in clinical practice. Changes in breathing pattern or mental stress, or even posture, alter immediately and completely the sympathetic/parasympathetic balance. This dynamic system could therefore not be properly studied by 'static' tests such as the levels of circulating neurotransmitters, and less so by their urinary catabolites. Bedside maneuvers to assess ANS function have included measurements of supine and standing pulse and blood pressure. Sustained drops in systolic blood pressure $(>20 \mathrm{mmHg})$ or diastolic blood pressure $(>10 \mathrm{mmHg})$ after standing for 3 minutes that are not associated with an increase in the pulse rate $>30$ beats per minute suggest autonomic deficit.

Opportunely, two research instruments have been recently introduced to aid in clinical research of cardiovascular autonomic function: heart rate variability analysis and the tilt table test. These two instruments have been used to study the pathogenesis of FM.

\section{Heart rate variability analysis}

The method is based on the well-known fact that the heart rate is not fixed, but varies from beat to beat constantly. The antagonistic effects of the sympathetic and parasympathetic branches of the ANS on the sinus node harmonize the periodic components of this constant variability. Heart rate variability can be studied in the time domain, where the basic units are milliseconds. Time-domain mathematical calculations include, among others, the standard deviation of all R-R interval durations as well as the percentage of adjacent pairs of R-R intervals that differ by more than $\mathbf{5 0}$ milliseconds from each other in a given time period. The higher time domain variability indexes signify more parasympathetic influx on the sinus node.

Heart rate variability can also be studied in the frequency domain using spectral analysis, where the basic units are Hertz (cycles per second). Pharmacological and clinical studies have established that the high-frequency-band spectral power reflects parasympathetic activity on the heart. These cycles of variability are harmonious with respiratory rhythm. The sympathetic division modulates a less frequent oscillations through the arterial baroreceptors. Since the two branches of the ANS have antagonistic effects on the sinus node, the low-frequency-band/high-frequency-band ratio is regarded as a reflection of sympathetic activity [5].

\section{Tilt table test}

The tilt table test is another useful tool to study orthostatic intolerance and syncope. The method is based on the physiological changes that occur after adopting an upright posture with pooling of approximately $700 \mathrm{ml}$ blood in the lower parts of the body. In normal circumstances, the ANS quickly compensates this relative volume loss by increasing vascular tone and cardiac output. This mechanism avoids hypotension and inadequate cerebral perfusion. Tilt table testing examines this response in a controlled environment. With passive orthostasis, additional stress is exerted on the sympathetic nervous system by blocking the influence of muscle contraction that could increase venous return. Subjects are supine for 30 minutes in the first step. The subject is then tilted upright for $30-45$ minutes at an angle of 
Table 1

\begin{tabular}{|c|c|c|c|c|}
\hline Reference & $\begin{array}{l}\text { Number of } \\
\text { patients }\end{array}$ & $\begin{array}{l}\text { Number of } \\
\text { controls }\end{array}$ & $\begin{array}{l}\text { Duration of heart } \\
\text { rate variability analysis }\end{array}$ & Main conclusion \\
\hline Martinez-Lavin and colleagues, 1998 [11] & 30 women & 30 women & 24 hours & Sympathetic hyperactivity \\
\hline Cohen and colleagues, 2000 [12] & 22 women & 22 women & 20 minutes & Sympathetic hyperactivity \\
\hline Raj and colleagues, 2000 [13] & 17 women & 14 women & 24 hours & Sympathetic hyperactivity \\
\hline Cohen and colleagues, 2001 [14] & 19 men & 19 men & 20 minutes & Sympathetic hyperactivity \\
\hline Stein and colleagues, 2004 [15] & $\begin{array}{l}26 \text { ( } 19 \text { women, } \\
7 \text { men) }\end{array}$ & $\begin{array}{l}36 \text { (18 women, } \\
18 \text { men) }\end{array}$ & 24 hours & $\begin{array}{l}\text { Sympathetic hyperactivity } \\
\text { in women, not in men }\end{array}$ \\
\hline Furlan and colleagues, 2005 [16] & 16 women & 16 women & 30 minutes & Sympathetic hyperactivity \\
\hline Ulas and colleagues, 2006 [17] & 34 women & 22 women & 30 minutes & Sympathetic hyperactivity \\
\hline
\end{tabular}

$60-80^{\circ}$. Pharmacological stimulation with isoproterenol is sometimes used as an additional step.

The normal responses to tilting consist of an increase in the heart rate of 10-15 beats per minute, an elevation of diastolic blood pressure of about $10 \mathrm{mmHg}$, and little change in systolic pressure. There are two types of abnormal responses. One such response is orthostatic hypotension, defined as a reduction of systolic blood pressure of at least $20 \mathrm{mmHg}$ or a reduction of diastolic blood pressure of at least $10 \mathrm{mmHg}$. This hypotension may induce syncope. The other type of abnormal response is postural orthostatic tachycardia, which consists of a sustained increase of heart rate of at least 30 beats per minute or a sustained pulse rate of 120 beats per minute. Tilt table testing has been used mostly to study syncope in patients with no evidence of structural heart disease [6].

\section{Autonomic nervous system dysfunction in fibromyalgia}

Evidence accumulated through the years has shown that autonomic dysfunction is frequent in FM. Bengtsson and Bengtsson published the first study in 1988, which was a controlled therapeutic trial of stellate ganglion blockade. They reported marked improvement of regional pain and tenderness as the response to this maneuver, in contrast to the lack of effect after a sham injection in the neck area [7]. Vaeroy and colleagues, using Doppler probes to measure skin blood flow in the hands, subsequently found that FM patients have less vasoconstrictory response to acoustic stimulation and cooling. These authors concluded that the cutaneous manifestations of FM previously interpreted as Raynaud's phenomenon should be reconsidered [8].

van Denderen and colleagues studied the influence of maximum exercise in 10 patients with FM and in 10 healthy sedentary control individuals. These authors found lower norepinephrine production together with the lower heart rate after exercises, suggesting a disturbance of the sympathetic reactivity in FM patients [9]. Elam and colleagues recorded muscle sympathetic activity with microelectrodes placed at the peroneal nerve level. They found no exaggerated sympathetic activity in FM subjects; nevertheless, these patients displayed less pronounced sympathetic activity as a response to muscle contraction [10].

Since the publication of these studies, little attention was paid to dysautonomia in FM until a decade ago, with the introduction of heart rate variability and tilt table testing in the study of FM pathogenesis.

\section{Heart rate variability analysis and tilt table testing in fibromyalgia}

Different groups of investigators have reported abnormal heart rate variability in subjects with FM [11-17]. Table 1 summarizes such data. All controlled studies in women have described, without exception, changes consistent with exaggerated sympathetic activity. There are two published heart rate variability analyses in men with $\mathrm{FM}$, one of which did not find signs of resting sympathetic hyperactivity.

Several groups of investigators have additionally tested the response of FM patients to different stressors [13,18-21]. The results are summarized in Table 2. Diverse reports agree with the concept that subjects with FM have a deficient sympathetic response to different types of stressors.

On the bases of this presented evidence it can be safely stated that patients with FM display prominent dysautonomia when studied by means of heart rate variability analysis and/ or the tilt table test. This dysautonomia can be characterized as a sympathetic nervous system that is persistently hyperactive but is hyporeactive to stress. This apparent paradox (sympathetic hyperactivity with hyporeactivity) nevertheless agrees with the basic physiological principle demonstrating that chronic hyperstimulation of the $\beta$-adrenergic receptors leads to receptor desensitization and downregulation. 
Table 2

\begin{tabular}{|c|c|c|c|c|}
\hline Reference & Type of stress test & $\begin{array}{l}\text { Number of } \\
\text { patients }\end{array}$ & $\begin{array}{l}\text { Number of } \\
\text { controls }\end{array}$ & Main conclusion \\
\hline $\begin{array}{l}\text { Martinez-Lavin and } \\
\text { colleagues, } 1997 \text { [18] }\end{array}$ & Active orthostatic stress & 19 & 19 & $\begin{array}{l}\text { Orthostatic sympathetic } \\
\text { derangement }\end{array}$ \\
\hline $\begin{array}{l}\text { Bou-Holaigah and } \\
\text { colleagues, } 1997 \text { [19] }\end{array}$ & Head-up tilt table test & 20 (17 female) & 20 (18 female) & $\begin{array}{l}\text { Hypotension in } 60 \% \\
\text { of patients ( } 0 \% \text { in controls) }\end{array}$ \\
\hline Raj and colleagues, 2000 [13] & Head-up tilt table test & 17 & 14 & $\begin{array}{l}\text { Positive test in } 64 \% \text { of } \\
\text { patients and } 21 \text { controls }\end{array}$ \\
\hline $\begin{array}{l}\text { Naschitz and colleagues, } \\
2001[20]\end{array}$ & $\begin{array}{l}\text { 'Discriminant score' during } \\
\text { head-up tilt table test }\end{array}$ & $\begin{array}{c}38 \\
\text { (67\% female) }\end{array}$ & $\begin{array}{c}30 \text { with chronic } \\
\text { fatigue syndrome } \\
\text { (58\% female), } \\
37 \text { normal } \\
(65 \% \text { female })\end{array}$ & $\begin{array}{l}\text { Discriminant score different in } \\
\text { fibromyalgia versus chronic } \\
\text { fatigue syndrome }\end{array}$ \\
\hline $\begin{array}{l}\text { Friederich and colleagues, } \\
2005 \text { [21] }\end{array}$ & $\begin{array}{l}\text { Mental stress, passive } \\
\text { orthostatism }\end{array}$ & 28 & 15 & Less sympathetic activation \\
\hline $\begin{array}{l}\text { Furlan and colleagues, } \\
2005[16]\end{array}$ & $\begin{array}{l}\text { Head-up tilt table test, } \\
\text { muscular sympathetic nerve }\end{array}$ & 16 (15 female) & 16 (15 female) & Decreased sympathetic response \\
\hline
\end{tabular}

It should be noted, however, that so far there is no autonomic measure that comes close to being sensitive or specific for FM. Different studies have shown that the FM groups have mean values significantly different from control groups, but there is considerable overlap between patients and control individuals. An explanation for this overlap could be the extremely variable behavior of the ANS. Abnormalities therefore cannot be detected on an individual basis but only when groups are compared. On the other hand, the heart rate variability findings reported by independent groups of investigators represent the most consistent alteration so far described in women with FM.

\section{Dysautonomia may explain the multisystem features of fibromyalgia}

ANS dysfunction may explain the diverse clinical manifestations of FM [22]. It has been suggested that, due to a ceiling effect, the hyperactive sympathetic nervous system of such patients becomes unable to further respond to different stressors, thus explaining the constant fatigue and morning stiffness these patients suffer. Relentless sympathetic hyperactivity may explain sleep disorders, anxiety, pseudoRaynaud's phenomenon, sicca symptoms, and intestinal irritability.

Kooh and colleagues performed concurrent analyses of heart rate variability and polysomnography in 10 subjects with FM and compared them with and an age/sex-matched controlled group. The authors reported changes consistent with nocturnal sympathetic hyperactivity. Such changes coincided with increased nocturnal arousal-awakening episodes [23]. Other investigators have shown that in normal sleeping persons electrocardiographic signs of sympathetic surge precede arousal/awakening episodes. This body of evidence suggests that sympathetic hyperactivity in FM causes the excessive arousal/awakening episodes [24].

\section{Sympathetically maintained pain concept}

For many years it has been assumed that abnormal activity of the sympathetic nervous system may be involved in the pathogenesis of chronic pain syndromes. This assumption was based mainly upon the observations that the pain is spatially correlated with signs of autonomic dysfunction, with the fact that blocking the efferent sympathetic supply to the affected region relieves the pain, and with the observation that norepinephrine injections rekindle the pain.

The sympathetically maintained pain concept has strong and ample foundations in the animal model. In contrast, the clinical information sustaining this pathogenesis is mostly anecdotal and does not, in most instances, fulfill the strict evidence-based medicine criteria [25].

\section{Animal studies of sympathetically maintained pain}

Under normal circumstances primary afferent nociceptors do not have catecholamine sensitivity. Under pathological conditions, however, particularly after trauma, a sympatheticafferent interaction can be established both at the peripheral and central levels.

In a rabbit model, after peripheral nerve injury, sympathetic stimulation and norepinephrine are excitatory for a subset of skin C-fibers nociceptors that express $\alpha_{2}$-adrenergic-like receptors [26]. Perhaps more germane to the pathogenesis of sympathetically maintained pain are the experimental models that have been extensively reproduced, in which 


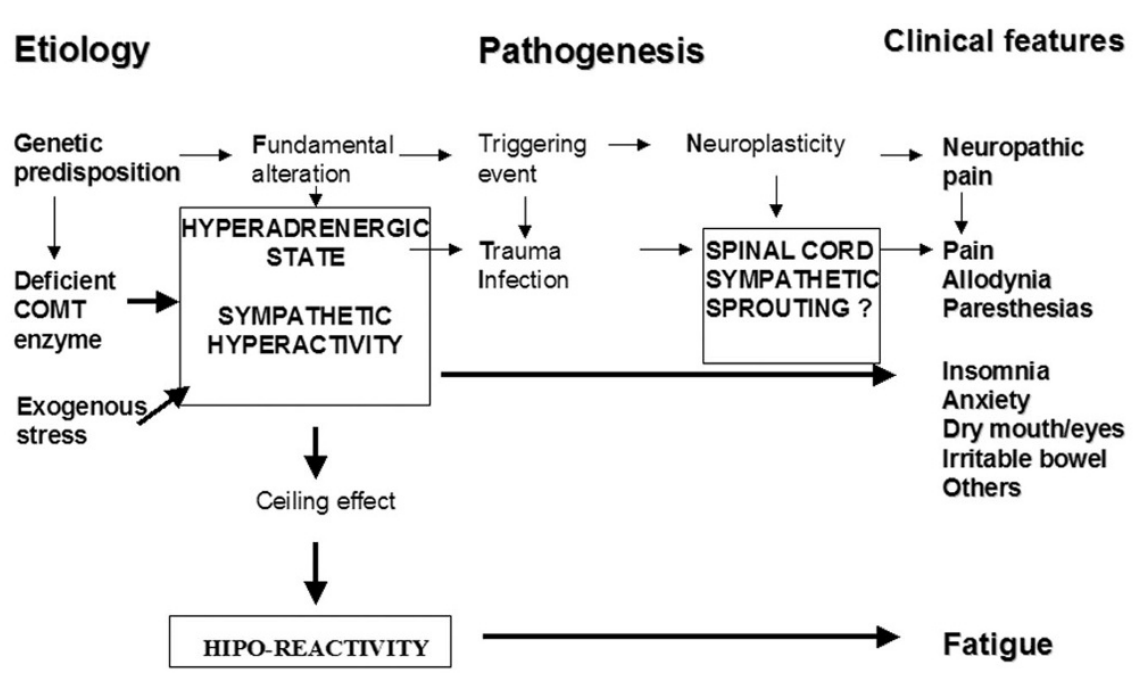

Theoretical etiopathogenetic mechanisms in fibromyalgia. See text for details. COMT, catechol-O-methyltransferase.

sympathetic sprouting at the dorsal root ganglia becomes apparent after nerve injury and forms basket-like structures around large-diameter axotomized sensory neurons; sympathetic stimulation can activate such neurons repetitively [27].

\section{Fibromyalgia as a sympathetically maintained pain syndrome}

The defining FM features (widespread pain plus tenderness at palpation on specific anatomical points), as well as the paresthesias that these patients have, could theoretically be explained by the pathogenesis known as 'sympathetically maintained pain'. This type of neuropathic pain is characterized by its frequent post-traumatic onset and by the presence of stimuli-independent pain perception accompanied by paresthesias and allodynia [25], which are precisely FM pain features. Different controlled studies have determined that subjects with FM have higher rates of physical or emotional trauma prior to the onset of their symptoms [28]. FM is clearly a stimulus-independent pain state since there is no underlying structural damage and inflammatory signs are conspicuously absent. Most patients with FM have paresthesias, as demonstrated in the original study that lead to the American College of Rheumatology criteria. In that original study, more than $80 \%$ of patients with FM had such sensory alteration. The studies of Simms and Goldenberg and of Martinez-Lavin and colleagues corroborated this high prevalence of paresthesias in FM $[29,30]$. Several groups of investigators have defined that the typical FM tender points reflect a state of generalized allodynia [31]. Additional arguments that favor the involvement of the sympathetic nervous system in the genesis of FM pain are the reports describing such pain as appearing submissive to sympatholytic maneuvers and to be rekindled by norepinephrine injections [32].
A prototype of sympathetically maintained pain syndrome is reflex sympathetic dystrophy (nowadays named Complex Regional Pain Syndrome type I). There are important points of coincidence between reflex sympathetic dystrophy and FM. Both conditions affect mostly females and have frequent post-traumatic onset. Both entities are characterized by stimuli-independent chronic pain, allodynia, paresthesias, and vasomotor instability. We therefore proposed that $F M$ is a generalized form of reflex sympathetic dystrophy [33].

Emerging genomic evidence supports the concept of FM as a sympathetically maintained pain syndrome. As mentioned above, the COMT enzyme is the main catecholamine catabolic pathway. Two different groups of investigators reported that subjects with FM less frequently have the val158-val genotype of the COMT gene when compared with healthy control individuals. This genotype induces an 'effective' catecholamine-clearing enzyme [34,35]. These preliminary results suggest that females that do not degrade catecholamines properly have higher risk to develop FM.

\section{Fibromyalgia as a neuropathic pain syndrome}

The International Association for the Study of Pain defines neuropathic pain as 'pain initiated or caused by a primary lesion or dysfunction of the nervous system' [36]. A more restrictive definition of neuropathic pain has been proposed recently [37]. It has been suggested that neuropathic pain should be diagnosed only when there is evidence of nervous system damage. Nevertheless, the clinical importance of neuropathic pain resides not in the nerve lesion itself, but in the resulting nerve dysfunction. There are other clinical syndromes classified as neuropathic pain in which no nervous system damage is obvious (for example, trigeminal neuralgia or reflex sympathetic dystrophy). 
It would be difficult to ascribe the concurrent presence of pain allodynia and paresthesias (which characterizes FM) to a pathogenesis different from an intrinsic nervous system alteration.

Another argument to consider FM a neuropathic pain syndrome comes from the reports of central nervous system sensitization. Patients with FM demonstrate abnormal temporal summation of pain [38] and have abnormal spinal cord reflexes [39]. Central sensitization is the expression of neuroplasticity and is the major cause of hypersensitivity to pain after injury. 'Central pain' is a type of neuropathic pain.

An additional argument for the neuropathic origin of $F M$ is a controlled study demonstrating that FM pain improves with antineuropathic medications [40].

\section{Treatment of autonomic dysfunction in fibromyalgia}

The current therapy for fibromyalgia is far from adequate. Nonpharmacologic therapies found partly effective are those interventions that also improve resting autonomic tone, such as graded aerobic exercises and cognitive-behavioral therapy [41].

There have been no double-blind investigations using adrenergic-blocking agents in FM. An open study using pindolol, however, reported beneficial effects [42]. It seems unlikely that adrenergic blocking agents may reverse FM pain completely since neuroplasticity is an irreversible alteration.

A dopamine agonist, pramipexole, has been found effective in a single-center double-blind investigation [43].

As previously mentioned, well-designed studies have shown that antineuropathic medications such as pregabalin are useful in FM [40].

\section{Conclusions}

Figure 1 synthesizes our proposal for the pathogenesis of FM. The algorithm is based on emerging scientific data. FM can be viewed as a disease of modern times, in which the main regulatory system of the body unsuccessfully attempts to adapt to contemporary stressful lifestyles. High-risk individuals would be those with defective catecholaminedegrading enzymes. Central to the pathogenesis of the illness is a constant hyperadrenergic state that could lead to a

This review is part of a series on Biology and therapy of fibromyalgia edited by Leslie Crofford.

Other articles in this series can be found at http://arthritis-research.com/articles/ review-series.asp?series=ar_fibromyalgia breakdown of the system. In such instances neuroplasticity takes place, establishing abnormal connections between the sympathetic nervous system and the nociceptive fibers. The resulting clinical syndrome would be a neuropathic type of pain. Dysautonomia can also explain other FM symptoms. Further research is needed to probe this novel paradigm.

\section{Competing interests}

The author declares that they have no competing interests.

\section{References}

1. Chrousos GP, Gold PW: The concepts of stress and stress system disorders. Overview of physical and behavioral homeostasis. JAMA 1992, 267:1244-1252.

2. Hoffman BB, Taylor P: Neurotransmission. the autonomic and somatic nervous system. In The pharmacological basis of therapeutics. Goodman \& Gilman's 10th ed. Edited by Hardman JG, Limbird LE. New York: McGraw-Hill; 2001:115-154.

3. Zubieta JK, Heitzeg MM, Smith YR, Bueller JA, Xu K, Xu Y, Koeppe RA, Stohler CS, Goldman D: COMT val158met genotype affects mu-opioid neurotransmitter responses to a pain stressor. Science 2003, 299:1240-1243.

4. Diatchenko L, Slade GD, Nackley AG, Bhalang K, Sigurdsson A, Belfer I, Goldman D, Xu K, Shabalina SA, Shagin D, et al.: Genetic basis for individual variation of pain perception and the development of a chronic pain condition. Hum Mol Genet 2005, 14:135-143.

5. Task Force of the European Society of Cardiology and the North American Society of Pacing and Electrophysiology: Heart rate variability standards of measurement, physiological interpretation, and clinical use. Circulation 1996, 93:1043-1065.

6. Hermosillo AG, Marquez MF, Jauregui-Renau K, Cardenas M: Orthostatic hypotension 2001. Cardiol Review 2001, 9:339-347.

7. Bengtsson A, Bengtsson M: Regional sympathetic blockade in primary fibromyalgia. Pain 1988, 33:161-167.

8. Vaeroy H, Qiao Z, Morkrid L, Forre O: Altered sympathetic nervous system response in patients with fibromyalgia. J Rheumatol 1989, 16:1460-1465.

9. van Denderen JC, Boersma JW, Zeinstra P, Hollander AP, van Neerbos BR: Physiological effects of exhaustive physical exercise in primary fibromyalgia syndrome (PFS): is PFS a disorder of neuroendocrine reactivity? Scand J Rheumatol 1992, 21: 35-37.

10. Elam M, Johansson G, Wallin BG: Do patients with primary fibromyalgia have an altered muscle sympathetic nerve activity? Pain 1992, 48:371-375.

11. Martinez-Lavin M, Hermosillo AG, Rosas M, Soto ME: Circadian studies of autonomic nervous balance in patients with fibromyalgia. A heart rate variability analysis. Arthritis Rheum 1998, 42:1966-1971.

12. Cohen H, Neumann L, Shore M, Amir M, Cassuto Y, Buskila D: Autonomic dysfunction in patients with fibromyalgia: application of power spectral analysis of heart rate variability. Semin Arthritis Rheum 2000, 29:217-227.

13. Raj RR, Brouillard D, Simpsom CS, Hopman WM, Abdollah H: Dysautonomia among patients with fibromyalgia: a noninvasive assessment $J$ Rheumato/ 2000, 27:2660-2665.

14. Cohen H, Neumann L, Alhosshle A, Kotler M, Abu-Shakra M, Buskila D: Abnormal sympathovagal balance in men with fibromyalgia. J Rheumatol 2001, 28:581-589.

15. Stein PK, Domitrovich PP, Ambrose K, Lyden A, Fine M, Gracely $\mathrm{RH}$, Clauw DJ: Sex effects on heart rate variability in fibromyalgia and Gulf War illness. Arthritis Rheum 2004, 51: 700-708.

16. Furlan R, Colombo S, Perego F, Atzeni F, Diana A, Barbic F, Porta A, Pace F, Malliani A, Sarzi-Puttini P: Abnormalities of cardiovascular neural control and reduced orthostatic tolerance in patients with primary fibromyalgia. J Rheumatol 2005, 32: 1787-1793.

17. Ulas UH, Unlu E, Hamamcioglu K, Odabasi Z, Cacki A, Vural O: Dysautonomia in fibromyalgia syndrome: sympathetic skin responses and RR interval analysis. Rheumatol Int 2006, 26: 383-387. 
18. Martínez-Lavín M, Hermosillo AG, Mendoza C, Ortiz R, Cajigas JC, Pineda C, Nava A, Vallejo M: Orthostatic sympathetic derangement in subjects with fibromyalgia. J Rheumato/ 1997, 24:714718.

19. Bou-Holaigah I, Calkins H, Flynn JA, Tunin C, Chang HC, Kan JS, Rowe PC: Provocation of hypotension and pain during upright tilt table testing in adults with fibromyalgia. Clin Exp Rheumatol 1997, 15:239-246.

20. Naschitz JE, Rozembaum M, Rosner I, Priselac RM, Shaviv N, Ahdoot A, Gaitini L, Eldar S, Yshurun E: Cardiovascular response to upright tilt in fibromyalgia differs from that in chronic fatigue syndrome. J Rheumato/ 2001, 28:56-60.

21. Friederich HC, Schellberg D, Mueller K, Biener C, Zipfel S, Eich W: Stress and autonomic dysregulation in patients with fibromyalgia syndrome. Schmerz 2005, 19:185-188.

22. Martinez-Lavin M, Hermosillo AG: Autonomic nervous system dysfunction may explain the multisystem features of fibromyalgia. Semin Arthritis Rheum 2000, 29:197-199.

23. Kooh M, Martínez-Lavin M, Meza S, Martín-del-Campo A, Hermosillo AG, Pineda C, Nava A, Amigo MC, Drucker-Colin R: Concurrent heart rate variability and polysomnography analyses in fibromyalgia patients. Clin Exp Rheumatol 2003, 21:529530.

24. Otzenberger H, Simon C, Gronfier C, Brandenberger G: Temporal relationship between dynamic heart rate variability and electroencephalographic activity during sleep in man. $\mathrm{Neu}^{-}$ rosci Lett 1997, 229:173-176.

25. Martinez-Lavin M: Fibromyalgia as a sympathetically maintained pain syndrome. Curr Pain Headache Rep 2004, 8:385389.

26. Sato J, Perl ER: Adrenergic excitation of cutaneous pain receptors induced by peripheral nerve injury. Science 1991, 251: 1608-1610.

27. McLachlan EM, Jäning $W$, Devor $M$, Michaelis $M$ : Peripheral nerve injury triggers noradrenergic sprouting within dorsal root ganglia. Nature 1993, 363:543-546.

28. Buskila D, Neumann L: Musculoskeletal injury as a trigger for fibromyalgia/posttraumatic fibromyalgia. Curr Rheumatol Rep 2000, 2:104-108.

29. Simms RW, Goldenberg DL: Symptoms mimicking neurologic disorders in fibromyalgia syndrome. J Rheumatol 1988, 15: 1271-1273.

30. Martinez-Lavin M, Lopez S, Medina M, Nava A: Use of the Leeds assessment of neuropathic symptoms and signs questionnaire in patients with fibromyalgia. Semin Arthritis Rheum 2003, 32:407-411.

31. Russell J: Advances in fibromyalgia: possible role for central neurochemicals. Am J Med Sci 1998, 315:377-384.

32. Martínez-Lavín M, Vidal M, Barbosa RE, Pineda C, Casanova JM, Nava A: Norepinephrine-evoked pain in fibromyalgia. A randomized pilot study ISCRTN 70707830. BMC Musculoskel Disord 2002, 3:2.

33. Martinez-Lavin M: Is fibromyalgia a generalized reflex sympathetic dystrophy. Clin Exp Rheumatol 2001, 19:1-3.

34. Gursoy S, Erdal E, Herken H, Madenci E, Alasehirli B, Erdal N: Significance of catechol-O-methyltransferase gene polymorphism in fibromyalgia syndrome. Rheumatol Int 2003, 23:104107.

35. Garcia-Fructuoso FR, Lao-Villadoniga Jl, Beyer K, Santos C: Relación entre genotipos del gen catecol-o-metiltransferasa y la gravedad de la fibromialgia. Reumatol Clin 2006, 2:168172

36. Merskey $\mathrm{H}$, Bogduk $\mathrm{N}$ : Classification of chronic pain. In IASP Task Force on Taxonomy. Seattle, WA: IASP Press; 1994.

37. Hansson PT, Lacerenza M, Marchettini P: Aspects of clinical and experimental neuropathic pain: the clinical perspective. In Neuropathic Pain: Pathophysiology and Treatment. Edited by Hansson PT, Fields HL, Hill RG, Marchettini P. Seattle, WA: IASP Press; 2001:1-19.

38. Staud R, Cannon RC, Mauderli AP, Robinson ME, Price DD, Vierck CJ: Temporal summation of pain from mechanical stimulation of muscle tissue in normal controls and subjects with fibromyalgia syndrome. Pain 2003, 102:87-95.

39. Desmeules JA, Cedraschi C, Rapiti E, Baumgartner E, Finckh A, Cohen P, Dayer P, Vischer TL: Neurophysiologic evidence of central sensitization in patients with fibromyalgia. Arthritis Rheum 2003, 48:1420-1429
40. Crofford L, Rowbotham MC, Mease PJ, Russel IJ, Dworkin RH, Corbin AE, Young JP, Lamoreaux LK, Martin SA, Sharma U: Pregabalin for the treatment of fibromyalgia syndrome: results of a randomized, double-blind, placebo-controlled trial. Arthritis Rheum 2005, 52:1264-1273.

41. Martinez-Lavin M: Management of dysautonomia in fibromyalgia. Rheum Dis Clin North Am 2002, 28:379-387.

42. Wood PB, Kablinger AS, Caldito GS: Open trial of pindolol in the treatment of fibromyalgia. Ann Pharmacother 2005, 39: 1812-1816.

43. Holman AJ, Myers RR: A randomized, double-blind, placebocontrolled trial of pramipexole, a dopamine agonist, in patients with fibromyalgia receiving concomitant medications. Arthritis Rheum 2005, 52:2495-2505. 